\title{
Results from a Longitudinal Early Literacy Intervention Study: Expected and Unexpected Outcomes
}

\author{
James W. Chapman
}

\begin{abstract}
Findings are presented from a two-year longitudinal study involving the Quick60 Foundation programme for beginning readers. This programme is a 32 week whole-class literacy curriculum that systematically and explicitly teaches key early literacy skills. End of Year 2 literacy performances of students receiving this programme during their first year of schooling were compared with students who received "regular" literacy instruction. Participants were in low decile Auckland schools, with large numbers of Māori and Pasifika students. At the end of Year 2, Quick60 students outperformed comparison students on reading book level, word knowledge, and reading accuracy; results for reading comprehension were not statistically significant but in the expected direction for Quick60 students. Surprisingly, students from home backgrounds rated by teachers as "normal" did not perform considerably better than students from "difficult" backgrounds. The results are discussed in terms of the benefits of explicit, code-orientated literacy instruction from the outset of schooling.
\end{abstract}

\section{Research Paper}

\section{Keywords:}

early literacy instruction; explicit instruction; low decile students; phonemic awareness; phonic skills; Quick60 Foundation Programme

\section{INTRODUCTION}

Despite efforts by different governments over the last 15 years or so, New Zealand continues to have a literacy problem (Tunmer \& Chapman, 2015). One of the key indicators of the extent of the problem is the high level of variability in scores from international surveys of reading achievement (Tunmer, Chapman, Greaney, Prochnow \& Arrow, 2013; Tunmer, Chapman \& Prochnow, 2003, 2004, 2006).

Concern over the literacy learning outcomes of young students in primary schools was noted in the Ministry of Education briefing document to the incoming Minister of Education following the 2011 general election. The Ministry wrote that:
... the gap between our high performing and low performing students remains one of the widest in the Organization of Economic Cooperation and Development (OECD). These low performing students are likely to be Māori or Pasifika and/or from low socio-economic communities. Disparities in education appear early and persist throughout learning, (Ministry of Education, 2011, p. 8).

The briefing concluded that producing equitable outcomes for students was "the greatest challenge" facing the schooling sector (Ministry of Education, 2011, p. 23).

The most recent international literacy survey of primary school students was the Progress in International Reading Literacy Study (PIRLS) in 2011 (Mullis, Martin, Foy \& Drucker, 2012). The general results were similar to those reported in 2001 and 2006 (Prochnow, Tunmer \& Greaney, 2015). No improvement in key literacy skills had occurred since the 2001 PIRLS survey, despite substantial increases in targeted funding designed to decrease disparities in learning outcomes.

A key reason for the continuing disparity in literacy learning outcomes is a rigid adherence in New Zealand to the view that learning to read is essentially like learning to speak, where both abilities are thought to develop "naturally" (Smith \& Elley, 1994, p. 81). The effect of this general view is that the importance in literacy acquisition on developing word-level decoding skills is downplayed or ignored because of the view that these skills are acquired naturally. The emphasis is placed instead on acquiring meaning from the story. This perspective is strongly promoted in publications, such as Reading in Junior Classes (Ministry of Education, 1991), The Learner as a Reader (Ministry of Education, 1996), Reading and Beyond (Ministry of Education, 1997), and Effective Literacy Practice in Years 1 to 4 (Ministry of Education, 2003).

Effective Literacy Practice (Ministry of Education, 2003), for example, states that "fluent readers ... draw on their prior knowledge and use all available sources of information simultaneously and usually 
unconsciously" (p. 30) when trying to identify unfamiliar words in text. Teachers are told to show beginning readers how to "cross-check predictions to ensure that they make sense and fit with other information" (p.130) in the story; "for beginning readers, cross-checking usually involves checking that their prediction of an individual word fits and makes sense (Ministry of Education, 2003, p. 130, emphasis added).

The major shortcoming of this approach is that it stresses the importance of using information from many sources in identifying unfamiliar words in text without recognising that skills and strategies involving phonological information are of primary importance in beginning literacy development. As Pressley (2006) pointed out, "the scientific evidence is simply overwhelming that letter-sound cues are more important in recognizing words ... than either semantic or syntactic cues" (p. 21), and that "teaching children to decode by giving primacy to semantic-contextual and syntacticcontextual cues over graphemic-phonemic cues is equivalent to teaching them to read the way weak readers read" (p. 164).

There is now a large body of research indicating that explicit, systematic instruction in the code relating spellings to pronunciations positively influences reading achievement, especially during the early stages of learning to read (Brady, 2011; Hattie, 2009; National Reading Panel, 2000; Snow \& Juel, 2005; Tunmer \& Arrow, 2013; Tunmer, Greaney \& Prochnow, 2015). After examining a wide range of sources, Snow and Juel (2005) concluded that explicit attention to alphabetic coding skills in early reading instruction is helpful for all students and crucial for some.

Although there is anecdotal information to suggest that some schools include explicit attention to the development of alphabetic coding skills, Ministry of Education publications, including Effective Literacy Practice in Years 1 to 4 (Ministry of Education, 2003), do not reflect such an emphasis. Given that this publication is now out-of-date in terms of contemporary research-based approaches to literacy instruction, it is timely for New Zealand schools to consider alternatives that reflect the significant developments that have occurred in our understanding of how children learn to read and why some struggle. Numerous literacy programmes have been developed overseas to take into account research developments in literacy acquisition and development (e.g., Jolly Phonics, Letterland, MultiLit). Such programmes are used in a number of New Zealand schools in place of, or as a part of, the 'regular' (whole language) approach to literacy instruction. At the same time, some New Zealand programmes that are firmly based on contemporary scientific research on literacy learning are emerging and warrant examination.

The purpose of the current study was to examine the effectiveness of an explicit literacy teaching programme, Quick60 Foundation (Iversen, 2013), for young students in low decile schools. The Quick60 Foundation programme was designed in New Zealand by Iversen for use with New Entrant/ Year 1 students, especially those who start school with few literacy skills, limited vocabularies and relatively little word knowledge. These students may or may not have English as their first language. The programme was developed to teach all of the necessary early literacy skills in an explicit and systematic way, including alphabet letter names, sounds, and formation, plus a bank of highfrequency words. Early phonemic awareness skills and comprehension strategies are taught alongside a progression of phonic skills for use in both reading and writing.

This paper focuses on specific aspects of a larger two-year longitudinal project. The following research question provided the focus for this paper: Does the code-orientated Quick60 Foundation programme lead to improved literacy learning outcomes of New Entrant/Year 1 students when compared with outcomes for students who receive their "normal" literacy instruction?

\section{METHOD}

\section{Selection of Schools}

Eighteen low decile (1-3) schools in the Auckland region with significant populations of Māori and Pasifika students were contacted towards the end of 2013 and invited to participate in the research project. The nature of the literacy programme was outlined, and they were asked to commit the New Entrant/Year 1 teacher to following the programme for the 90-minute literacy block each day throughout 2014. Schools were given the choice of using the Quick60 Foundation programme (intervention) or serving as a comparison school with the option of receiving the Qucik60 programme at a later time if they chose to. Five schools agreed to participate in the study. Three schools indicated that they were not interested in using the Quick60 programme but that they were willing to serve as a "comparison" group as they continued with their normal literacy programme.

\section{Students}

At the start of the project in February 2014, the sample comprised 104 students from eight schools. Seventy-five students were in the Quick60 group and 29 students were in the comparison group. In terms of gender, 40 boys and 35 girls were in the Quick60 group; 17 boys and 12 girls were in the 
comparison group. In each of the eight schools, the students in the study constituted the whole class group at the start of the study. Other students were phased in as New Entrants during the first year of the project but data were not collected for them.

The mean age of the total sample at the start of the project was 64.3 months $(S D=4.0)$, which is around 5 years 4 months, and the modal age was 63 months (5 years 3 months). For the Quick60 group, the mean age at the start of the project was 65.25 months ( $S D=4.25)$, and for the comparison group the mean age was 62.31 months $(S D=2.11)$. This difference of 3 months is statistically significant, $t(102)=3.55, p<.01$. An examination of the distribution of ages revealed that 67 percent of the students in the project were younger than 5 years 5 months. The remainder were older, with the oldest student 6 years 8 months. More students 5 years 5 months or older were in the Quick60 group than the comparison group: 41 percent $(n=31)$ versus 10 percent $(\mathrm{n}=3)$.

The majority of students in the Quick60 group were Māori (56 percent), with Pasifika (25 percent), Pākehā (13 percent), and Asian (4 percent) representing other ethnicities. For the comparison group, the majority of students were Pasifika (59 percent), followed by Māori (31 percent), Asian (3 percent), and "Other" (7 percent). No Pākehā students were in the comparison group.

Fifty percent of students were in decile 1 schools, 24 percent in decile 2 schools, and 26 percent in decile 3 schools. Quick60 group students were spread across the three decile rankings: $1=39$ percent; $2=25$ percent; $3=36$ percent. Students in the comparison group were from decile 1 (79 percent) and decile 2 (21 percent) schools.

\section{Quick60 Foundation Programme}

The Quick60 Foundation programme is underpinned by the Vygotskian concept of the zone of proximal development (Wood, Bruner \& Ross, 1976). Both the instructional sequence within and across lessons and the Foundation materials are designed to move learners from where they can achieve with assistance to where they can function independently, continually raising the baseline bar. The student reading-books steadily increase in difficulty. Scaffolding of skills is provided by lesson demonstrations followed by joint participation, guided practice and independent learning, leading to internationalisation. Multiple opportunities are provided to promote overlearning within and across the instructional strands.

The Quick60 Foundation programme is a 32-week whole-class literacy curriculum that systematically teaches all the necessary early literacy skills in an explicit way. Students are taught the vocabulary for basic science, social studies and maths concepts and how to compare, contrast and group objects with similar attributes. They are also taught alphabet letter names, sounds, and formation, plus a bank of high-frequency words. Eight early phonemic awareness skills and eight early comprehension strategies are taught alongside a progression of phonic skills for use in both reading and writing. Students learn simple sentence writing including print conventions, how to hear and record the sounds in words in order, and how to generate new words from known spellings. In addition, they practise how to write short passages covering a variety of factual and narrative genres.

The Quick60 Foundation programme was designed for teaching in the 90-minute literacy block. Components can be taught in any order. While teachers are working with groups for guided reading, other students are provided the opportunity to work independently at learning centres.

The programme incorporates a variety of teaching methodologies. These include oral language through language experiences, shared reading using "Big Books", guided reading, and interactive and guided writing. Time is provided for independent practise, consolidation, revision and extension.

The guided reading lesson follows the same format each day and is based on previous research (Iversen \& Tunmer, 1993; Iversen, Tunmer \& Chapman, 2005). Both these studies adapted the Reading Recovery format by including phonemic awareness activities into the daily lesson (Iversen \& Tunmer, 1993), and by teaching this adapted lesson to two students at a time rather than one (Iversen et al., 2005). The Quick60 guided reading lesson has been modified further for use with groups of up to six students and the in-class model has two 20 minute sessions rather than one 40 minute session.

Teacher resources include a programme overview, daily lesson plans that contain daily and weekly ongoing assessments, colour-coded check sheets to record oral reading behaviour, data point sheets to summarise data, and various blacklines to copy for teaching and to support independent student work.

Teachers in the Quick60 schools were supplied with all the materials they needed to implement the programme, including detailed daily lesson plans. However, they were not provided with any additional professional development. Fidelity of programme implementation was not considered to be an issue. Rather, teachers were viewed as professionals who were capable of best-deciding how to use the programme materials for their students. Specific details of the programme's scope and sequence, together with a description of the 
materials are included in a more comprehensive report on this research project (Chapman, 2016).

\section{Assessments}

A number of assessments were administered to students by an independent research assistant at the beginning of Year 1 and end of Year 2. Assessments at the start of Year 1 included alphabet knowledge, receptive vocabulary ${ }^{1}$, onset and rime awareness ${ }^{2}$, and phonemic awareness ${ }^{3}$. At the end of Year 2, assessments included reading comprehension and accuracy, word knowledge, spelling, reading book level, pseudoword pronunciation and sounds, and receptive vocabulary. Full details of the assessments are available in Chapman (2016).

\section{RESULTS}

\section{Start of Year 1}

Of considerable importance was the finding that there were no significant differences between the Quick60 and comparison groups in regards to receptive vocabulary. Based on raw scores for the British Picture Vocabulary Scale (a measure of receptive vocabulary: Dunn et al., 2009), the Quick60 group mean was $57.08(S D=15.20)$ and the comparison mean was 58.69 (SD = $15.13) ; t(65)=0.43, p=.67$. The general language knowledge of the two groups was similar at the start of the study.

Because the Quick60 group included a larger number of older students who had received more schooling than the younger students, I compared the means of the older Quick60, younger Quick60, and comparison students using a one-way analysis of variance (ANOVA). The results for receptive vocabulary, rime awareness, and onset awareness were not statistically significant. Summary data are presented in Table 1.

Statistically significant results were found for letter knowledge $(F(2,96)=11.38, p<.001)$ and phonemic awareness $(F(2,88)=6.33, p=.01)$. For letter knowledge, the older Quick60 students had higher scores than both the younger Quick60 and the comparison students, and the younger Quick60 students had higher scores than the comparison students. The higher scores for the older students may be a function of having been at school longer. In addition, the higher scores for the Quick60 students compared to comparison students may be due to teachers working with Quick60 from the start of school in February 2014, which was before the completion of the baseline assessments.

Table 1

Summary Data for Time 1 (Baseline) Variables

\begin{tabular}{ccccccc}
\hline & \multicolumn{2}{c}{$\begin{array}{c}\text { Younger } \\
\text { Quick60 }\end{array}$} & \multicolumn{2}{c}{$\begin{array}{c}\text { Older } \\
\text { Quick60 }\end{array}$} & \multicolumn{2}{c}{ Comparison } \\
\hline Variables & Mean & SD & Mean & SD & Mean & SD \\
\hline $\begin{array}{c}\text { Letter } \\
\text { knowledge }\end{array}$ & 39.23 & 31.34 & 63.24 & 38.02 & 22.77 & 24.03 \\
\hline $\begin{array}{c}\text { Receptive } \\
\text { vocabulary }\end{array}$ & 53.64 & 13.58 & 61.81 & 16.44 & 57.04 & 14.93 \\
\hline Onset & 3.09 & 3.61 & 4.19 & 3.95 & 2.96 & 4.12 \\
\hline Rime & 2.75 & 3.59 & 3.90 & 3.90 & 2.27 & 3.58 \\
\hline $\begin{array}{c}\text { Phonemic } \\
\text { awareness }\end{array}$ & 4.02 & 7.15 & 13.39 & 22.58 & 1.12 & 5.49 \\
\hline
\end{tabular}

\section{End of Year 2 Data}

The final assessment phase of the project occurred in November and December 2015. Data were available for a maximum of 58 Quick60 students and 26 comparison students (see Table 2).

Statistically significant effects were not found for pseudoword phonemes ${ }^{4}$, spelling, and reading comprehension. One significant effect for a reading process variable was found for pseudoword pronunciation, $F(2,76)=3.67, p=.03$. Both younger and older Quick60 groups outperformed the comparison students.

For the reading outcome variables, the word knowledge test resulted in a statistically significant effect, $F(2,78)=3.15, p=.05$ : younger Quick60 students obtained higher scores than comparison students, with a relatively large effect size of 0.79 . Reading book level also resulted in a significant effect, $F(2,78)=9.28, p<.001$. Both Quick60 groups of students obtained higher book level scores than the comparison students, and the younger Quick60 students obtained marginally $(p=.06)$ higher levels than the older Quick60 students. The effect size for the difference between the young Quick60 students and the comparison students was approximately 1.5 , which is very large.

\footnotetext{
${ }^{1}$ Receptive vocabulary refers to the words a person understands when hearing or reading them.

${ }^{2}$ Onset awareness is understanding and identifying the initial consonant or consonant blend in a word before the vowel (" $\mathrm{c}$ " in cat). Not all words have onsets. Rime refers to the vowel and final consonants in the word ("at" in cat).

${ }^{3}$ Phonemic awareness is the ability to hear and manipulate sounds in spoken words; it is not phonics.

${ }^{4}$ Pseudowords are fake words which have no meaning but are pronounceable. They are considered to be the best measure of phonological processing skills, and therefore ideal for identifying difficulties in understanding and manipulating the sounds in spoken language.
} 
Reading accuracy also produced a significant effect, $F(2,76)=3.80, p=.03$. Both Quick60 groups significantly outperformed the comparison students. The effect size for the younger Quick60students contrasted with the comparison students was approximately .84.

Table 2

Summary Data for Time 5 (End of Year 2)

\begin{tabular}{ccccccc}
\hline & \multicolumn{2}{c}{$\begin{array}{c}\text { Younger } \\
\text { Quick60 }\end{array}$} & \multicolumn{2}{c}{$\begin{array}{c}\text { Older } \\
\text { Quick60 }\end{array}$} & \multicolumn{2}{c}{ Comparison } \\
\hline Variables & Mean & SD & Mean & SD & Mean & SD \\
\hline $\begin{array}{c}\text { Receptive } \\
\text { vocabulary }\end{array}$ & 83.30 & 11.33 & 84.60 & 14.99 & 82.48 & 9.77 \\
\hline $\begin{array}{c}\text { Pseudo } \\
\text { pronunciation }\end{array}$ & 12.79 & 8.14 & 12.87 & 11.33 & 6.96 & 6.23 \\
\hline $\begin{array}{c}\text { Pseudo sounds } \\
74.55\end{array}$ & 25.41 & 67.26 & 33.12 & 58.65 & 29.52 \\
\hline $\begin{array}{c}\text { Reading book } \\
\text { level }\end{array}$ & 20.42 & 4.58 & 17.28 & 7.97 & 13.04 & 6.43 \\
\hline Burt word test & 37.58 & 11.08 & 32.96 & 16.44 & 28.70 & 11.71 \\
\hline Comprehension & 10.34 & 5.42 & 9.35 & 5.84 & 6.52 & 3.65 \\
\hline $\begin{array}{c}\text { Reading } \\
\text { accuracy }\end{array}$ & 31.48 & 12.91 & 29.30 & 19.10 & 20.52 & 13.13 \\
\hline Spelling & 20.97 & 2.63 & 20.32 & 4.34 & 18.96 & 2.55 \\
\hline
\end{tabular}

End of Year 2 reading outcome variables were examined in relation to home circumstances by means of a two-way (group x circumstances) ANOVA. More students in the Quick60 group were rated by teachers as having difficult home circumstances (58 percent) than in the comparison group (19 percent).

Statistically significant differences were observed between the 'non-challenging' and 'challenging' background groups for word knowledge and reading book level, but not for the tests of comprehension, accuracy or spelling. None of the group (Quick60 vs. comparison) by circumstances (non-challenging vs. challenging) interaction effects was statistically significant. Although students from challenging home backgrounds in the Quick60 group tended to lag behind those from more normal backgrounds, the differences are relatively small (see Table 3).

Table 3

Summary Data for Time 5 (End of Year 2) Reading Outcome Variables as a Function of Home Circumstances

\begin{tabular}{ccccc}
\hline & \multicolumn{2}{c}{ Non-Challenging } & \multicolumn{2}{c}{ Challenging } \\
\hline Variables & Mean & SD & Mean & SD \\
\hline Reading book level & 18.09 & 6.15 & 16.33 & 7.59 \\
\hline Burt word test & 35.64 & 11.82 & 31.31 & 14.65 \\
\hline Reading comp & 9.45 & 5.58 & 8.27 & 4.71 \\
\hline Reading accuracy & 29.13 & 15.33 & 25.76 & 15.31 \\
\hline Spelling & 20.42 & 2.90 & 20.05 & 3.66 \\
\hline
\end{tabular}

\section{DISCUSSION}

The results of this study suggest that the Quick60 Foundation programme is effective with students in low decile schools, which include large numbers of Māori and Pasifika students. At the end of Year 2, Quick60 students significantly outperformed comparison students on reading book level, word knowledge, and reading accuracy. Although results for reading comprehension were not statistically significant, they were in the expected direction, with younger Quick60 students obtaining higher scores than the comparison students. By the end of Year 2, the younger Quick60 students were reading on average at their chronological age level of seven years, whereas the comparison students were close to one year behind in terms of reading book level, and six months behind in terms of word knowledge. Given that low decile students tend to lag behind students in higher decile schools from the start of schooling and beyond (Tunmer \& Chapman, 2015), the results from this study are very promising.

The results come with a note of caution. Students in the Quick60 group had higher scores than those in the comparison group on some variables at the start of the project. These differences were partly due to the older students in the Quick60 group who had already received more schooling, during the previous year than the other students. However, there are two factors that address this issue.

Teachers of students in the Quick60 group began using the programme at the very start of the school year and often before the initial assessments were completed. From the outset of schooling the Quick60 programme provides explicit and systematic exposure to the basic language skills required for reading acquisition, together with the rapid development of alphabet letter knowledge. This approach is likely to result in reasonably rapid foundational literacy learning (Snow \& Juel, 2005).

The second factor relates to the different age distribution of students in the Quick60 group. The younger Quick60 students started at the beginning of Year 1 with lower scores than the older Quick60 students on the key variables of letter knowledge and phonemic awareness. By the end of the project, however, the younger Quick60 students "caught up" to the older Quick60 students on most variables. This finding suggests that explicit and systematic teaching of key language-related reading skills from the time of school entry is associated with significant reading development outcomes over at least the first two years of schooling. These outcomes were superior to those normally achieved by students in low decile schools.

There was one unexpected finding. Students from complex and challenging home backgrounds, often involving poverty, poor housing and health, parental 
unemployment, crime and substance abuse, frequently do not achieve age-appropriate learning outcomes (Boston, 2013; Gibb, Fergusson \& Horwood, 2012; Ministry of Education, 2016). There was only a relatively small degree of evidence in this study for a negative impact of poor home circumstances on literacy learning. Over half of the Quick60 students who remained in the study at the end of Year 2 were rated by their teachers as having complex and challenging home circumstances. Although there were statistically significant effects for word knowledge, reading level, and spelling, the differences between the means were relatively small. Further, the means for Quick60 students from difficult home backgrounds were higher than the means for comparison students from home backgrounds not rated by teachers as challenging. These differences were not statistically significant, but they suggest that participating in the Quick60 programme appears to have been beneficial and may have helped to offset the disadvantages associated with challenging family circumstances.

An important question relates to the performance of students from non-challenging home backgrounds: why did they not perform much better than those students from challenging home backgrounds? Students from non-challenging home backgrounds had higher school attendance rates, according to their teachers, than those from challenging backgrounds. If quality instruction is provided, being in school should lead to considerably better literacy learning outcomes than having erratic school attendance.

\section{CONCLUSION}

This study provides evidence to suggest that the Quick60 programme has contributed to beneficial literacy learning outcomes for students, especially for those who were New Entrants at the start of the project. The programme materials used by teachers from "Day 1" are consistent with research showing the benefits of explicit and systematic instruction in foundational skills. Further, the programme was in place only during the students' first year of schooling. This appears to have set the groundwork for gains that were made during the second year of schooling, a finding that is consistent with other studies (e.g., Kimmel \& Griffith, 2010; Porche, Pallante \& Snow, 2012; Stahl, Keane \& Simic, 2013; Tunmer, Chapman, Ryan \& Prochnow, 1998).

To overcome the high variability in literacy learning outcomes, with disproportionately large number of Māori and Pasifika students disadvantaged at the outset of schooling, new approaches to literacy instruction, based on an overwhelming consensus of scientific research, are needed. Such approaches have been developed in other countries, such as Australia, Canada, the United Kingdom, and the United States, with considerable success. The Quick60 Foundation programme developed in New Zealand provides a promising alternative to traditional literacy instruction that appears to benefit students in low decile schools, and particularly those from Māori and Pasifika backgrounds.

These results from this study are compelling in the context of low decile schools with large numbers of Māori and Pasifika students. Such students often start school with limited amounts of literate cultural capital (Tunmer \& Chapman, 2015). Programmes, such as Quick60, that are based on scientific evidence and that emphasise the importance of developing appropriate language and code skills for reading acquisition, provide a promising alternative to the status quo for those schools that are highly motivated to overcome inequitable literacy learning outcomes among their students. As we know, doing the same thing typically gets the same results. This has been the case for literacy instruction over at least the last decade and a half. To change the generally negative direction of literacy learning outcomes for many New Zealand children will require changes to the nature of literacy instruction. The Quick60 programme is a good, research-based example of a positive change.

\section{REFERENCES}

Boston, J. (2013, May). Improving educational performance: Why tackling child poverty must be part of the solution. Paper presented at the Symposium on "Poverty Impacts on Learning", Victoria University of Wellington, Wellington.

Brady, S. (2011). Efficacy of phonics teaching for reading outcomes: Indications from post-NRP research. In S. Brady, D. Braze, \& C. Fowler (Eds.), Explaining individual differences in reading: Theory and evidence (pp. 69-96). New York, NY: Psychology Press.

Chapman, J.W. (2016). Research report on the predictive abilities and effectiveness of assessment tools for monitoring literacy programmes in primary schools, involving the Quick60 programme. Palmerston North: Massey University. DOI: 10.13140/RG.2.1.1962.9046

Connelly, V., Johnston, R., \& Thompson, G. B. (2001). The effects of phonics instruction on the reading comprehension of beginning readers. Reading and Writing, 14, 423-457.

Dunn, L.M., Dunn, D.M., Sewell, J., Styles, B., Brzyska, B., \& Shamsan, Y. (2009). British picture vocabulary test (3rd ed.). London: GL Assessment.

Gibb, S.J., Fergusson, D.M., \& Horwood, L.J. (2012). Childhood family income and life outcomes in adulthood: Findings from a 30-year longitudinal study in New Zealand. Social Science and Medicine, 74, 1979-1986. 
Hattie, J. A. (2009). Visible learning: A synthesis of over 800 meta-analyses relating to achievement. London: Routledge.

Iversen, S.A. (2013). Quick60 foundation. Auckland: Iversen Publishing Ltd.

Iversen, S.A., \& Tunmer, W.E. (1993). Phonological processing skills and the reading recovery program. Journal of Educational Psychology, 85, 112-125.

Iversen, S.A., Tunmer, W.E., \& Chapman, J.W. (2005). The effects of varying group size on the reading recovery approach to preventive early intervention. Journal of Learning Disabilities, 38, 256-272.

Kimmel, S. J., \& Griffith, P. L. (2010). Evaluation: Practical applications for closing achievement gaps. In M. C. McKenna, S. Walpole \& N. J. Conrad (Eds.), Promoting early reading: Research, resources, and best practices (pp. 143-163). New York: Guilford Press.

Ministry of Education (1991). Reading in junior classes. Wellington: Learning Media Ltd.

Ministry of Education (1996). The learner as a reader. Wellington: Learning Media Ltd.

Ministry of Education (1997). Reading and beyond. Wellington, New Zealand: Learning Media Ltd.

Ministry of Education (2003). Effective literacy practice in years 1 to 4. Wellington: Learning Media Ltd.

Ministry of Education (2011). Briefing to the incoming minister. Wellington: Author.

Ministry of Education (2016). Children living in low income households. Retrieved from: https://www.educationcounts.govt.nz/ indicators/definition/family-and-communityengagement/3981

Mullis, I.V.S., Martin, M.O., Foy, P., \& Drucker, K.T. (2012). PIRLS 2011 international results in reading. Chestnut Hill, MA: TIMSS \& PIRLS International Study center, Boston College. Retrieved from: http://timss.bc.edu/pirls2011/international-resultspirls-html

National Reading Panel (2000). Teaching children to read. An evidence-based assessment of the scientific research literature on reading and its implications for reading instruction. Washington, DC: National Institute for Child Health and Human Development.

Porche, M. V., Pallante, D. H., \& Snow, C. E. (2012). Professional development for reading achievement: Results from the collaborative language and literacy instruction project (CLLIP). Elementary School Journal, 112, 649-671. doi: $10.1086 / 665008$
Pressley, M. (2006). Reading instruction that works: The case for balanced teaching. New York: The Guilford Press.

Prochnow, J.E., Tunmer, W.E., \& Greaney, K.T. (2015). Findings from New Zealand's participation in the progress in international reading literacy study in 2001, 2006, and 2011. In W.E. Tunmer \& J.W. Chapman (Eds.), Excellence and equity in literacy education: The case of New Zealand (pp. 23-40). Basingstoke, England: Palgrave Macmillan.

Smith, J.W.A., \& Elley, W.B. (1994). Learning to read in New Zealand. Auckland: Heinemann.

Snow, C. E., \& Juel, C. (2005). Teaching children to read: What do we know about how to do it? In M. J. Snowling \& C. Hulme (Eds.), The science of reading: A handbook (pp. 501-520). Oxford: Blackwell.

Stahl, K. A. D., Keane, A. E., \& Simic, O. (2013). Translating policy to practice: Initiating RTI in urban schools. Urban Education, 48, 350-379. doi: 10.1177/0042085912451755

Tunmer, W. E., \& Arrow, A. W. (2013). Reading: Phonics instruction. In J. Hattie \& E. Anderman (Eds.), International guide to student achievement (pp. 316-319). London: Routledge.

Tunmer, W.E., \& Chapman, J.W. (Eds.) (2015). Excellence and equity in literacy education: The case of New Zealand. Basingstoke, England: Palgrave Macmillan.

Tunmer, W. E., Chapman, J. W., \& Prochnow, J. E. (2003). Preventing negative matthew effects in at-risk readers: A retrospective study. In B. Foorman (Ed.), Preventing and remediating reading difficulties: Bringing science to scale (pp. 121163). Timonium, MD: York Press.

Tunmer, W. E., Chapman, J. W., \& Prochnow, J. E. (2004). Why the reading achievement gap in New Zealand won't go away: Evidence from the PIRLS 2001 international study of reading achievement. New Zealand Journal of Educational Studies, 39, 127-145.

Tunmer, W. E., Chapman, J. W., \& Prochnow, J. E. (2006). Literate cultural capital at school entry predicts later reading achievement: A seven year longitudinal study. New Zealand Journal of Educational Studies, 41, 183-204.

Tunmer, W.E., Chapman, J.W., Greaney, K.T., Prochnow, J.E., \& Arrow, A.W. (2013). Why the New Zealand literacy strategy has failed and what can be done about it: Evidence from the progress 
in international reading literacy study (PIRLS) 2011 and reading recovery monitoring reports. Australian Journal of Learning Difficulties, 18, 139-180.

Tunmer W. E., Chapman J. W., Ryan H. A., \& Prochnow J. E. (1998). The importance of providing beginning readers with explicit training in phonological processing skills. Australian Journal of Learning Disabilities, 3, 4-14.

Tunmer, W.E., Greaney, K.T., \& Prochnow, J.E. (2015). Pedagogical constructivism in New Zealand literacy education: A flawed approach to teaching reading. In W.E. Tunmer \& J.W. Chapman (Eds.), Excellence and equity in literacy education: The case of New Zealand (pp. 121-144). Basingstoke, England: Palgrave Macmillan.

Wood, D., Bruner, J., \& Ross, G. (1976). The role of tutoring in problem solving. Journal of Child Psychology and Child Psychiatry, 17, 89-100.

I am grateful to MSA Charities for their financial support of this research project. Without this support, the project could not have been undertaken.

This research project was undertaken because the developer of the Quick60 programme, Dr Sandra Iversen, is a Masters and PhD graduate of Massey University. The programme she has developed provides an example of theory and research from her post-graduate study being used to develop a programme designed to enhance literacy learning outcomes of school students.

I declare that I have no financial or other interests in the Quick60 programme or any related products developed and distributed by Iversen Publishing. My interest is solely academic and the pursuit of better literacy learning outcomes for New Zealand students.

\section{AUTHOR PROFILE}

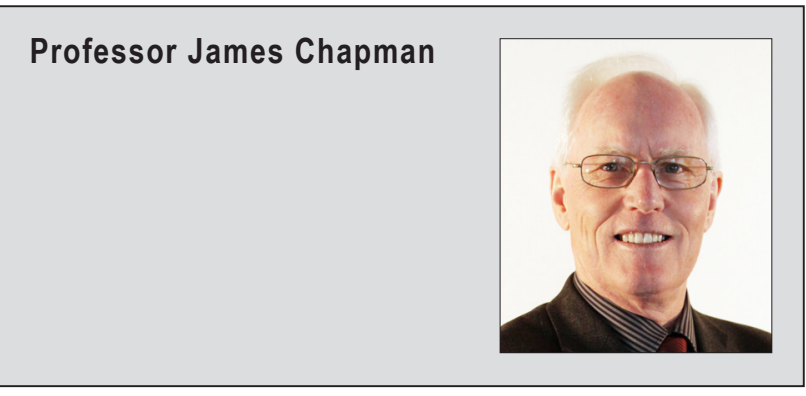

Professor James Chapman is Professor of Educational Psychology in The College of Humanities and Social Sciences at Massey University. He received his M.A. (with distinction) in education from Victoria University of Wellington, and his Ph.D. in Educational Psychology from the University of Alberta, Canada, specializing in cognitive-motivational factors associated with learning disabilities. Professor Chapman trained as a secondary school teacher and taught for two years before undertaking doctoral studies in Canada. Following the completion of his $\mathrm{PhD}$, he joined Massey University in 1980. He served for $8 \frac{1}{2}$ years as Head of the Department of Learning and Teaching, and 10 years as Pro Vice-Chancellor of the College of Education. He has published over 100 journal articles, book chapters and books on learning disabilities, special education, literacy learning difficulties, early literacy development, reading intervention, and self-concept factors in academic achievement. He has served on the editorial boards of numerous academic journals, and completed a 4-year term as President of the International Academy for Research in Learning Disabilities. In 1999 he was co-winner of the International Reading Association's Dina Feitelson Award for Excellence in Research. He is currently Co-Principal Investigator of a New Zealand Ministry of Education-funded longitudinal literacy research project (Enhancing Literacy Learning Outcomes for Year 1 Children) focusing on literacy learning in Year 1 children and professional development for teachers of Year 1 children.

Email: J.Chapman@massey.ac.nz 